\title{
Monitoramento de plantas a partir de imagens multiespectrais
}

\section{Gabriel Sette*, Leandro R. Ximenes.}

\section{Resumo}

O uso de imagens multiespectrais para sensoriamento remoto é uma das técnicas de maior interesse dentro da chamada agricultura de precisão. Neste trabalho o processamento destas imagens através do software QGIS permitiu determinar padrões de crescimento de plantas a partir da análise temporal de índices de vegetação.

\section{Palavras-chave:}

Agricultura de Precisão, Imagens Multiespectrais, Índices de Vegetação.

\section{Introdução}

A agricultura de precisão é o nome dado à aplicação de um conjunto de tecnologias que permite uma maior eficiência nos processos agrícolas, como no auxílio à identificação de culturas, na automatização do processo de colheita, no tratamento dos solos, entre outros [1]. Dentro da agricultura de precisão, o uso de imagens multiespectrais de satélite tem se mostrado oportuno para sistemas de sensoriamento remoto, pois estas fornecem mais informações que as imagens de uma única banda no espectro eletromagnético usadas em sistemas de sensoriamento remoto convencionais $[1,2]$.

Este projeto busca explorar imagens multiespectrais obtidas de satélites, através do uso do software livre Quantum GIS (QGIS), para monitorar o crescimento de plantas através da análise temporal dos chamados índices de vegetação.

\section{Resultados e Discussão}

Entre vários índices de vegetação estudados neste projeto, foi utilizado o Normalized Difference Vegetation Index (NDVI) na Figura 1, usando imagens multiespectrais de satélite da região de Limeira, no interior de São Paulo. Estas imagens foram obtidas do banco de dados do Earth Explorer, disponibilizadas gratuitamente pelo United States Geological Survey (USGS).

Para o processamento da imagem e o devido cálculo dos índices de vegetação foi utilizado o software Quantum GIS (QGIS). Este software apresenta uma calculadora onde é possível calcular o NDVI através das bandas da imagem multiespectral como NDVI $=($ Rnir$\mathrm{Rr}) /(\mathrm{Rnir}+\mathrm{Rr}$ ), em que Rnir é o valor do pixel para a imagem do infravermelho próximo (Near InfraRed - NIR, banda 5 do satélite Landsat 8) e Rr é o valor do mesmo pixel para a imagem da banda do vermelho (banda 4 do mesmo satélite). O NDVI varia entre 0 e 1 , onde a proximidade ao 1 indica a presença de vegetação [3].

Para o monitoramento do crescimento de plantações, foi realizada uma análise temporal do NDVI calculado das imagens de satélite do Landsat- $8 \mathrm{em}$ diferentes períodos do ano para a mesma região geográfica. Aqui a Figura 1 é usada para efeito ilustrativo da variação do NDVI com o tempo, mostrando os meses de Março e Outubro de 2016. Para uma melhor visualização, o nível de variação do NDVI entre 0 a 1 é indicado pelos tons entre o vermelho e o verde.

Através das curvas de variação do NDVI com o tempo, e da comparação destas com curvas de diferentes culturas (cana-de-açúcar, laranja, etc) é possível estimar o tipo de plantação em cada região de plantio e o estágio de plantação cultura.
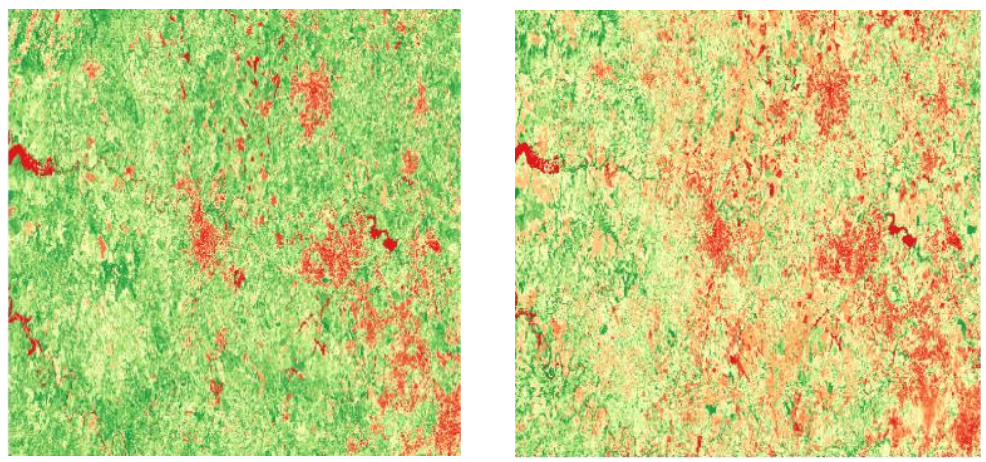

Figura 1.Índice NDVI para o mês de Março (esquerda) e Outubro (direita).

\section{Conclusões}

As imagens multiespectrais são de grande utilidade para a agricultura de precisão, pois permitem analisar como é a cobertura vegetal da região de interesse, bem como auxiliar na identificação de culturas utilizando exclusivamente imagens de satélite.

Neste projeto de iniciação científica foi utilizado um software livre para identificar padrões de crescimento de culturas através de uma análise temporal de índices de vegetação calculados a partir de imagens multiespectrais

[1] BERNARDI, A. C. de C.; NAIME, J de M.; RESENDE, A. V. De; BASSOI, L. H.; INAMASU, R. Y. (Ed.). Agricultura de precisão: resultados de um novo olhar. Brasília, DF: Embrapa, 2014. 596 p.

[2] KUIAWSKI, A.C. M. B. Utilização de Técnicas de agricultura de precisão no manejo e controle de plantas daninhas. Universidade Federal de Santa Catarina - Campus Curitibanos, 2013.

[3] ROUSE, J. W.; HASS, R. H.; SCHELl, J. A.; DEERING, D. W. Monitoring vegetation systems in the great plains with ERTS. In: Earth Resources Technology Satellite-1 Symposium, 3, Washington, 1973. Proceedings. Washington: NASA, v.1, 317 P., 1973. 